\title{
Radiographic manifestations of experimental aluminum toxicity in growing bone
}

\author{
Ramiro J. Hernandez, M.D. ${ }^{1}$, Aileen B. Sedman, M.D. ${ }^{2}$, David M. Smid, M.D. ${ }^{1}$, \\ and William G. Goodman, M.D. ${ }^{3}$ \\ Departments of ${ }^{1}$ Radiology and ${ }^{2}$ Pediatrics, C.S. Mott Children's Hospital, University of Michigan Hospitals, \\ Ann Arbor, Michigan, \\ ${ }^{3}$ Sepulveda V.A. Medical Center, Sepulveda, California, USA
}

\begin{abstract}
To evaluate the effect of aluminum on growing bone in the presence of normal renal function, the following experiment was performed. Eight littermate pair-fed pigs ( 5 weeks old) were randomly assigned to one of two study groups: control $\mathrm{C}, n=4$, or aluminum treated $\mathrm{Al}, n=4$. Daily intravenous injections of either aluminum $1.5 \mathrm{mg} / \mathrm{kg} /$ day (Al group) or vehicle only (C group) were given during the 8-week duration of the study. The radiographic findings which appeared in the aluminum-treated group and not in the controls consisted of areas of sclerosis in the submetaphyseal regions and the periphery of epiphyses. In addition there was separation of the anterior tibial tubercle. The growth plates did not increase in width despite the presence of osteomalacia and histologic evidence of extensive deposition of aluminum in bone. The area of sclerosis visualized in the radiographs correlated histologically with thickened bony trabeculae. The increased width of these trabeculae is attributable to an increase in primary spongiosum and broadened seams of osteoid.
\end{abstract}

Key words: Aluminum - Osteomalacia - Pig - Radiographic - Computed tomography

Increased body aluminum burden is associated with a form of osteomalacia that does not benefit from vitamin $D$ therapy. The biochemical characteristics associated with aluminum-induced osteomalacia are a normal or high plasma calcium and phosphate concentration, a normal or only slightly elevated plasma alkaline phosphatase concentra-

Address reprint requests to: R. Hernandez, M.D., Section of Pediatric Radiology, University of Michigan Hospitals, C.S. Mott Children's Hosp. C3123/0252, 1500 E. Medical Center Drive Ann Arbor, MI 48109-0252, USA tion, and a low or normal plasma parathyroid hormone concentration [11].

In patients with chronic renal failure, the inability of the kidneys to clear the absorbed aluminum is exacerbated by the oral ingestion of phosphate-binding aluminum or parenteral exposure to aluminum containing solutions $[1,15,20]$. In the absence of renal failure, increase in the body aluminum burden can occur in patients receiving longterm hyperalimentation from contaminants in the solutions [12, 13, 16, 21].

Several reports have described the radiographic appearance of aluminum toxicity $[2,4,19]$. These reports largely deal with the appearance of the bone scan, except for the report by Andreoli et al. [2], who described the characteristic radiographic findings of aluminum toxicity in children with chronic renal failure.

The purpose of this report is to describe the radiographic appearance of aluminum toxicity in the growing bones of pigs whose renal function is normal. Although many animal models have been previously used as a means of studying aluminum toxicity, most work has been done in rats whose bone growth differs markedly from the human pattern in that no internal remodeling occurs. Pigs were used in this study because of their similarity to the human pattern of remodeling and rapid early growth and also because they provide more plentiful bone for histologic examinations.

\section{Materials and methods}

Eight littermate pigs 5 weeks old were housed in individual pens for the duration of the study. All animals had free access to water and were maintained on standard pig chow (Pig Growing Ralston Purina Co. Chicago, IL) containing 1.6\% calcium and $0.57 \%$ phosphorus.

Polyurethane catheters were surgically placed in the left jugular vein of each animal. Patency of the venous catheters was maintained by daily irrigations with heparinized saline throughout the study. 

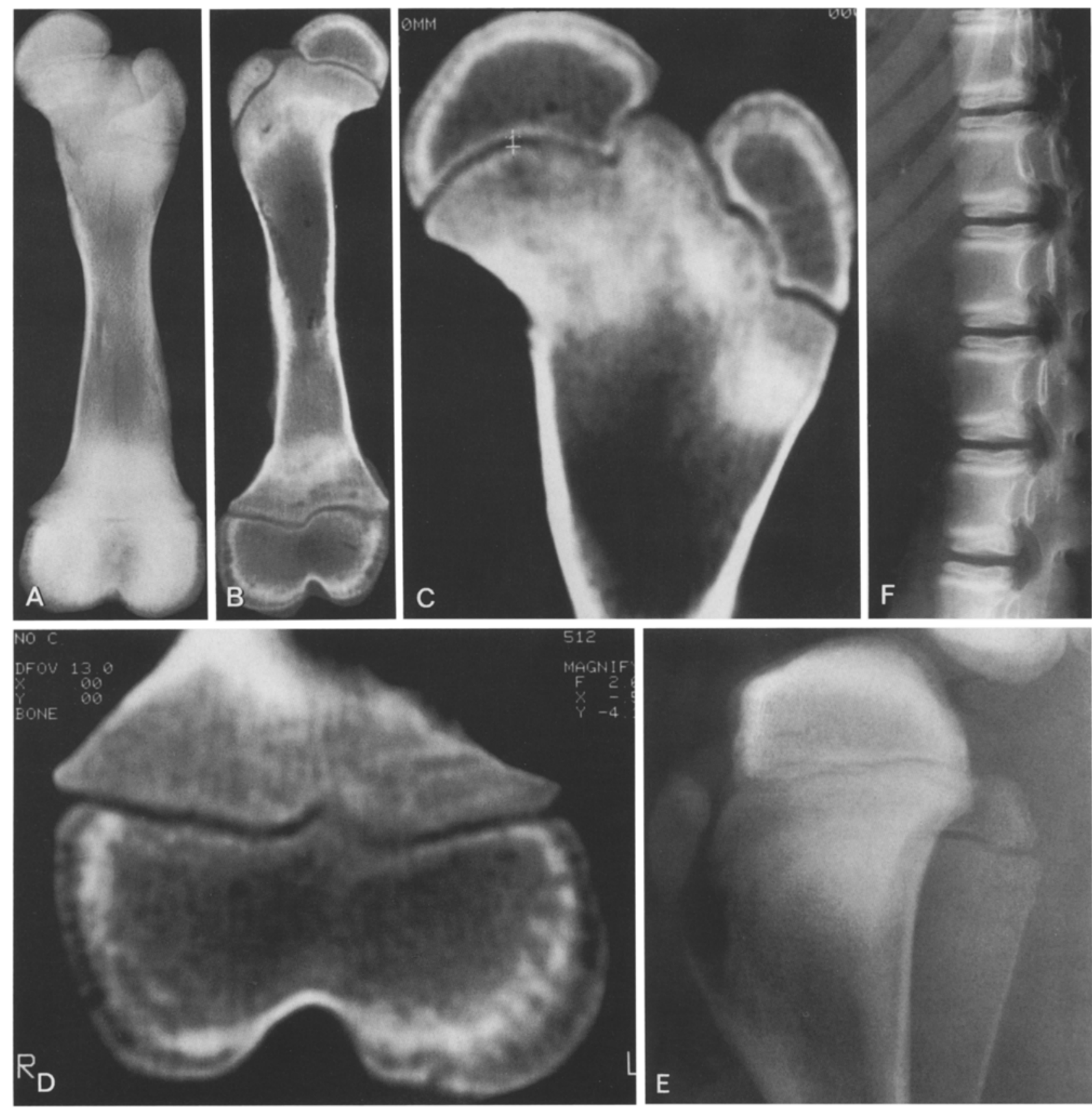

Fig. 1. A Radiograph of femur of pig 6 treated with Al. There is increased density in the metaphysis and epiphysis. B CT of same femur demonstrates areas of sclerosis in the metaphysis and in the periphery of the epiphysis. $\mathrm{C}$ Magnified area of the proximal femur demonstrating the metaphyseal areas of sclerosis. Areas of increased density at the periphery of the epiphysis. D Magnified area of the distal femur demonstrating the area of sclerosis in the periphery of the epiphysis. $\mathbf{E}$ Lateral view of proximal tibia demonstrating separation of the anterior tibial tubercle. F Lateral radiograph of the spine demonstrating area of sclerosis in the metaphyseal region

Individual pigs were assigned at random to one of two study groups: control $(\mathrm{C}, n=4)$ and aluminum treated ( $\mathrm{Al}$, $n=4)$. One week after the placement of intravenous catheters, injections of aluminum were begun. For the animals in $\mathrm{Al}$, aluminum chloride was added to $50 \mathrm{ml}$ of $0.9 \%$ saline as vehicle, and the solution was infused over a period of $10 \mathrm{~min}, 7$ days each week for 8 weeks. The dose of elemental aluminum was $1.5 \mathrm{mg} / \mathrm{kg}$ body weight/day. Control animals received daily in- fusions of vehicle only. To assure similar weight gain, animals in $\mathrm{C}$ group were pair-fed with those in $\mathrm{Al}$ group.

All animals were given intravenous injections of tetracycline $\mathrm{HCl} 20 \mathrm{mg} / \mathrm{kg} 8$ days and 1 day before being sacrificed. Two days before death, a 24-hour collection of urine was obtained. The animals were killed by cardiac puncture and exsanguination while under ketamine and pentobarbitol anesthesia.

Radiographs of the lower extremities and spine were per- 

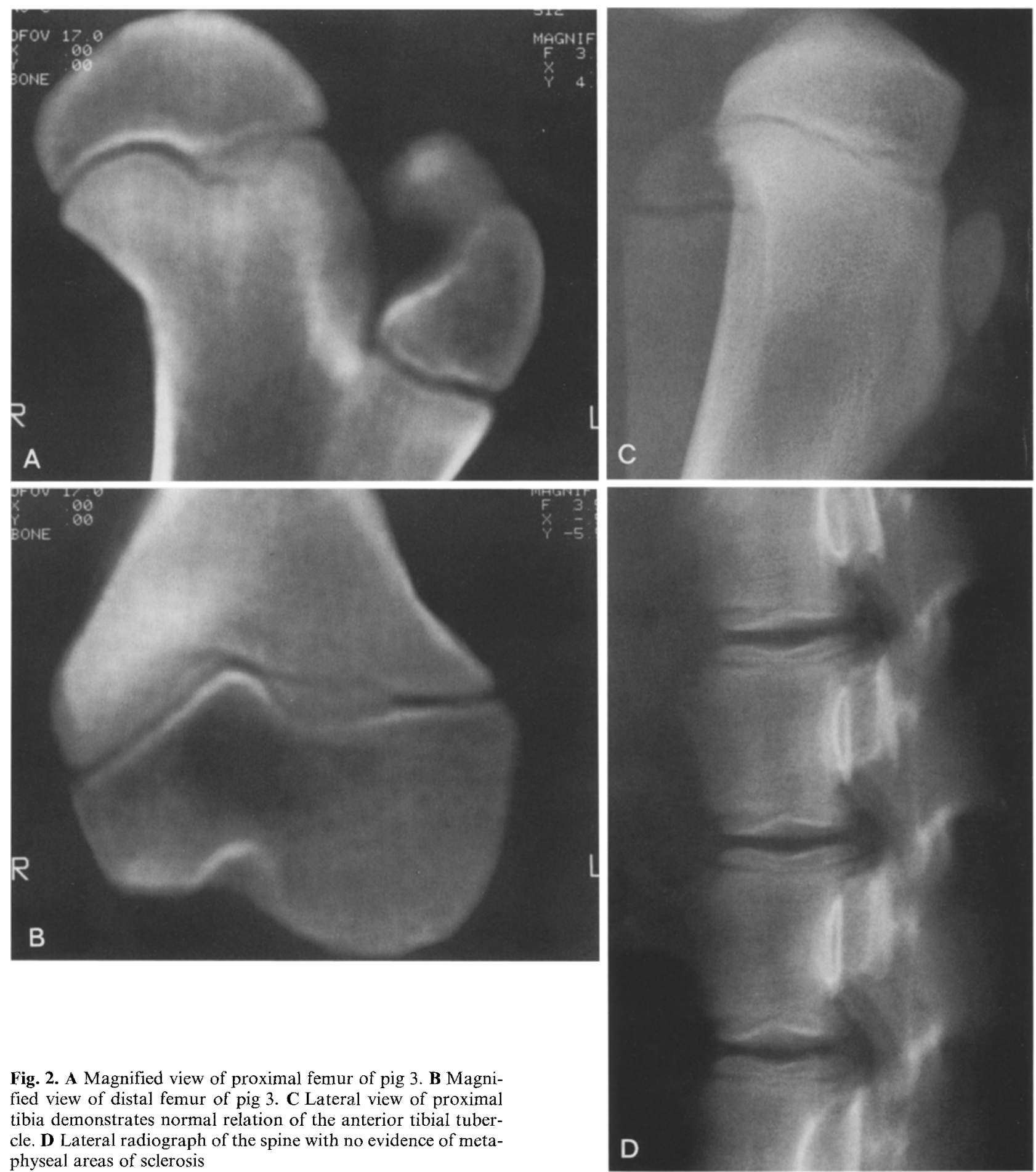

Fig. 2. A Magnified view of proximal femur of pig 3. B Magnified view of distal femur of pig 3. C Lateral view of proximal tibia demonstrates normal relation of the anterior tibial tubercle. D Lateral radiograph of the spine with no evidence of metaphyseal areas of sclerosis

formed 2 days before death. Quantitative histologic studies were done on specimens of trabecular bone obtained from three different skeletal sites, two in the proximal tibia and one in the distal femur. The standardized site of biopsy was an area on the lateral surface of the left femur, $4 \mathrm{~cm}$ proximal to the lateral femoral condyle. In the tibia, the specimens were obtained from the epiphysis and the metaphysis, $4 \mathrm{~cm}$ below the growth plate. Sections were also stained using the aurine tricar-

boxylic acid method for the histochemical determination of the aluminum content of bone.

The contralateral femur and tibia were isolated after the soft tissues were removed, and radiographs were obtained. In addition, the femurs were scanned with a GE 9800 CT scanner, using the bone algorithm to enhance trabecular detail. The same window center and level were used for the display of all bones. Electronic calipers were used to measure the growth plates of 
the distal femurs in the computed tomography (CT) scans. Nonquantitative light microscopy of the metaphyseal region adjacent to the growth plate and of the periphery of the epiphysis was performed. The widths of growth plate, the osteoid, and the mineralized cartilage, and the thickness of the trabeculae were determined.

\section{Results}

Quantitative histology criteria confirmed osteomalacia in all aluminum-treated animals. Sedman et al. reported these results in detail [22]. The bone volume was not statistically different in the $\mathrm{Al}$ and $\mathrm{C}$ groups. The aluminum content of bone was substantially increased.

In all the aluminum-treated pigs, radiographs showed areas of sclerosis in the submetaphyseal region and in the periphery of the epiphysis, and separation of the anterior tibial tubercle (Figs. 1, $2)$. The growth plates remained the same width in the treated and the untreated groups. The width of the growth plates in the untreated group had a mean of $0.1 \mathrm{~cm}$ range $(0.1-0.12 \mathrm{~cm})$; in the treated group the mean was $0.13 \mathrm{~cm}$ range $(0.1-0.21 \mathrm{~cm})$. Only one of the pigs showed widening of the growth plate (Fig. 3). Bands of thickened bony trabeculae in the epiphysis and metaphysis correspond histologically to the sclerotic changes that are seen radiographically (Fig. 4). The increased width of these trabeculae is attributable to an increase in primary spongiosum and to broadened osteoid seams. In addition, areas of fibrosis and hemorrhage were present which suggested microfractures. The cause of the separation of the anterior tibial tubercle is not clear, but most probably represents a chronic avulsion fracture.

\section{Discussion}

In patients with chronic renal failure the body aluminum burden can be increased as a result of aluminum present in dialysate or from the ingestion of aluminum-containing phosphate binders. Food is not a significant source since the aluminum content in most food is less than $0.1 \mathrm{mg} / \mathrm{g}$ [14]. There is, however, approximately $500 \mathrm{mg} / \mathrm{g}$ of aluminum in $\mathrm{Al}(\mathrm{OH})_{3}$ medication. When renal function is normal, most of the aluminum load from oral ingestion can be handled by the kidneys $[9,10,17]$. Contaminants in solutions used in parenteral nutrition may overwhelm the kidneys and result in an increase in the body aluminum burden $[12,13,16$, 21]. Besides casein hydroxylate, other components of the intravenous solution (phosphate salts, calcium salts, heparin) have been found to have a high aluminum content [21]. As little as $2 \mathrm{mg} /$ day of
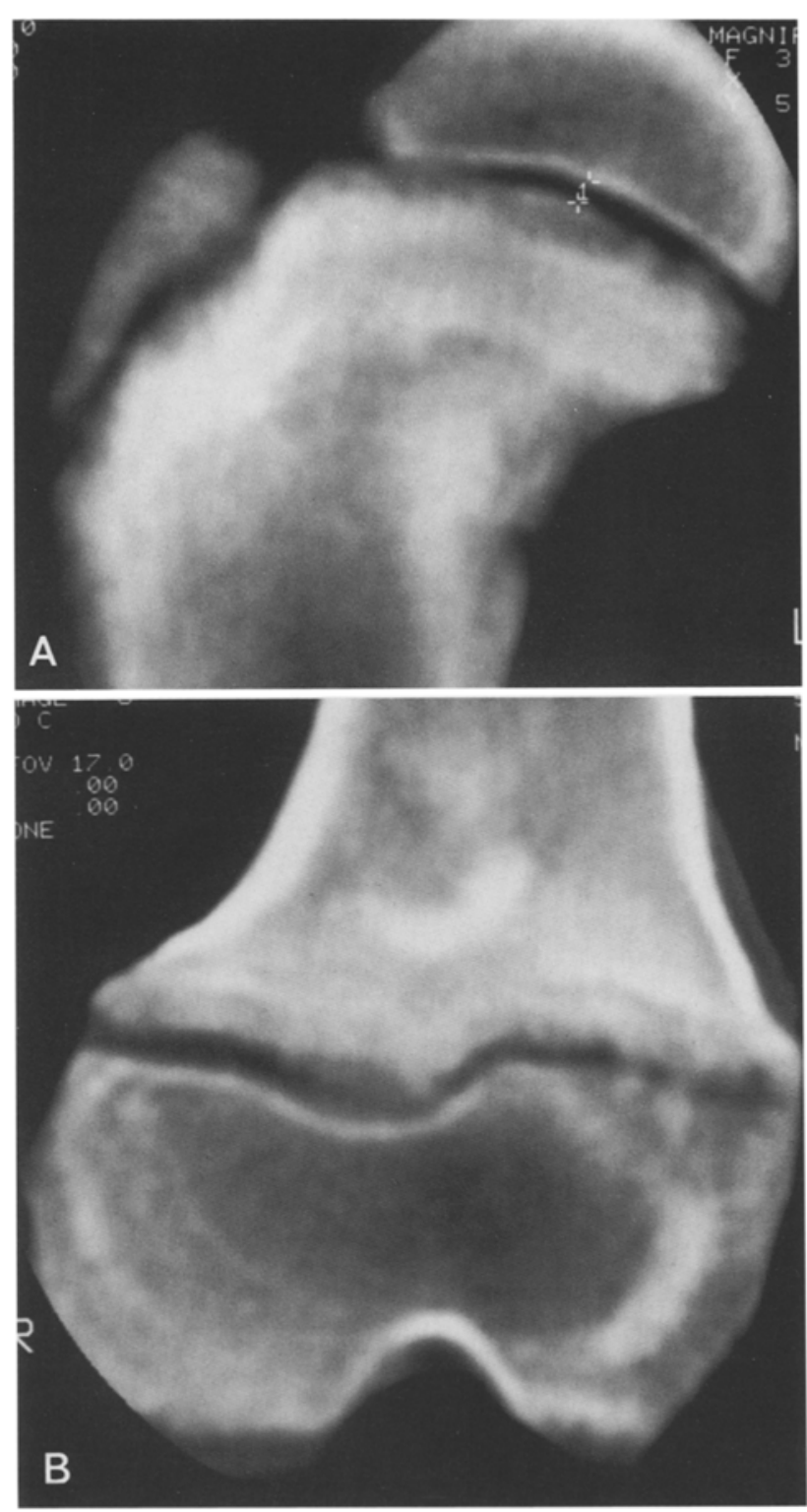

Fig. 3. Magnified view of the distal (A) and proximal (B) ends of the femur of Al-treated pig 4 demonstrating widening and irregularity of the growth plate

aluminum given parenterally is enough to cause symptomatic bone disease [13].

The radiographic appearance of aluminum-induced bone toxicity in children has been described and includes osteopenia, pathological fractures, fraying of the metaphyses of the long bones, and widening of the growth plate [2]. In our experimental model, except for the separation of the anterior tibial tubercle which probably represents some form of an avulsion fracture, none of these changes was present. Instead, areas of sclerosis in the submetaphyseal regions and in the epiphyses were present. The zones of sclerosis seen in the radio- 


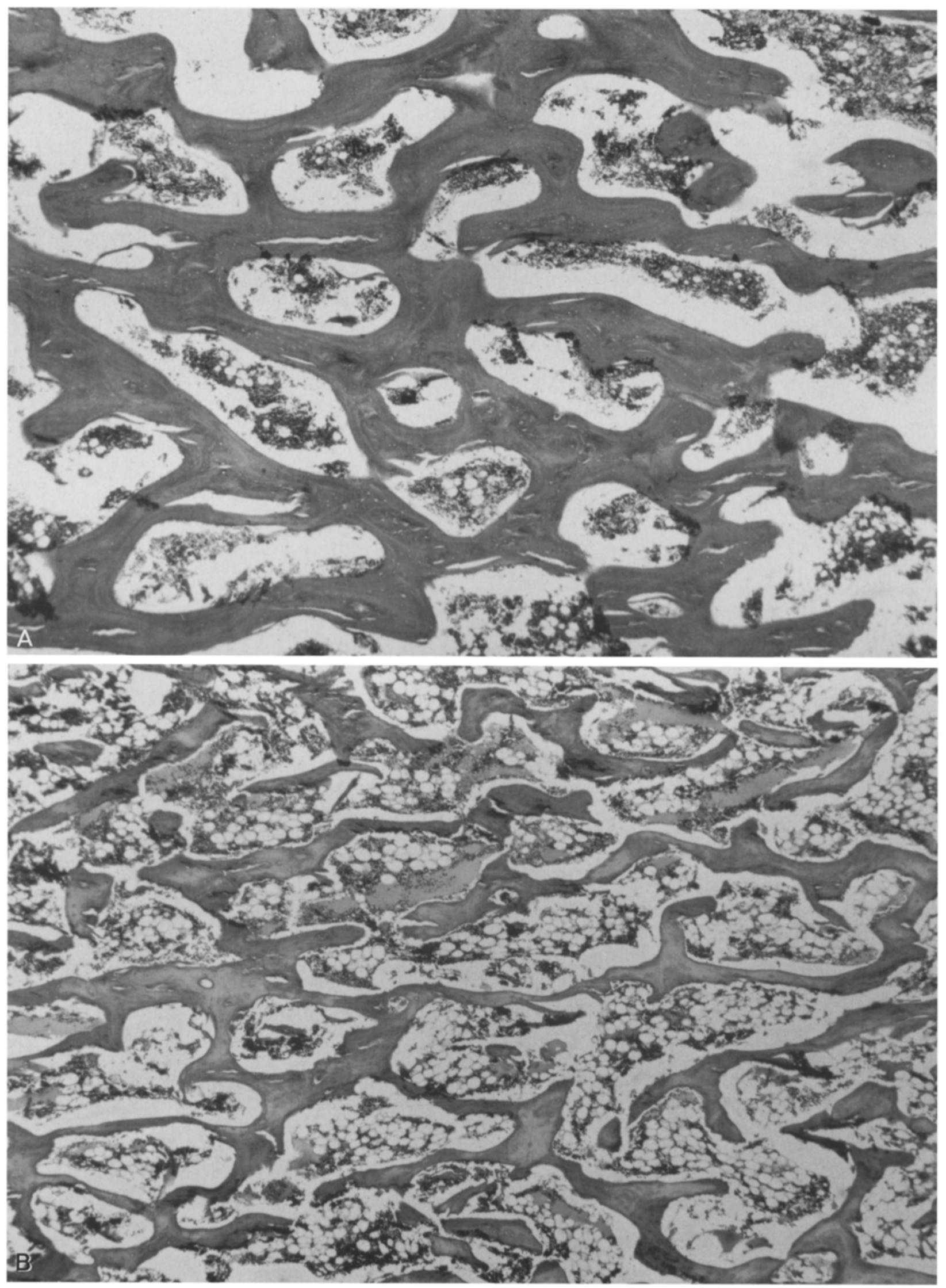

Fig. 4A, B. Low power view of area of sclerosis in proximal metaphysis of treated pig (A) and similar area in the untreated pig (B): Note the thickened and irregular trabeculae in (A) 


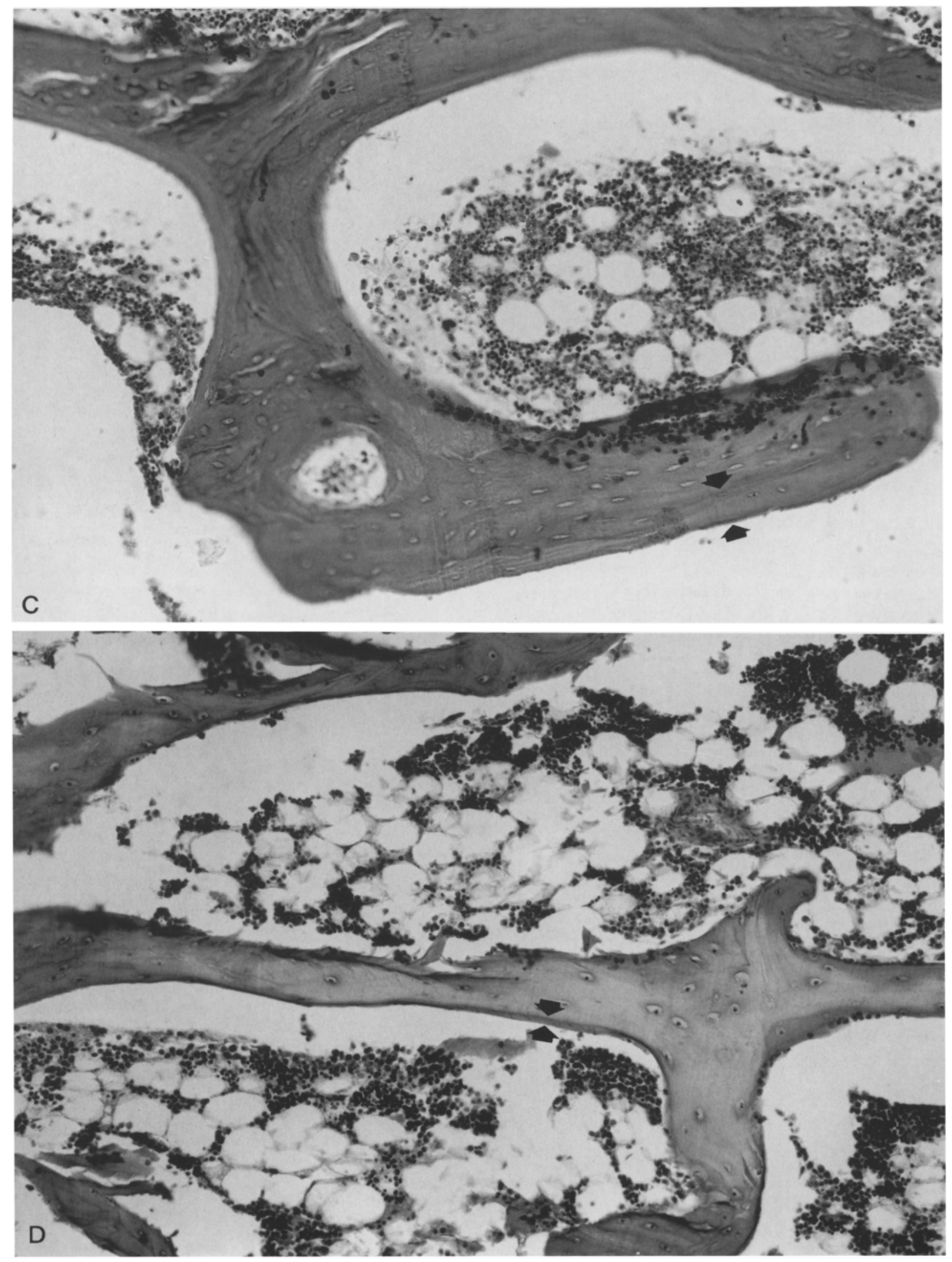

Fig. 4 C, D. High power view of the same area in a treated pig (C) and an untreated pig (D). In the treated pig $(C)$ the trabeculae are thickened with broad osteoid seams (arrows) 
graphs of the Al-treated group corresponded to the areas of thickened and compacted trabeculae seen by conventional histology. This change in trabecular size was demonstrated by conventional histology but not by quantitative histology. The discrepancy in the findings can be explained by the fact that bone samples were obtained from different sites. The samples for quantitative histology were obtained from areas with a normal radiographic appearance located $4 \mathrm{~cm}$ proximal to the growth plate, whereas the areas evaluated by conventional histology were closer to the growth plate and the epiphyseal cartilage. The thickening of the trabeculae results from the widening of the osteoid seams and the presence of primary spongiosum. The presence of primary spongiosum in the trabeculae suggests a disruption in the normal generation of mineralized cartilage and its subsequent remodeling to normal trabecular bone.

The mechanism by which osteomalacia develops during aluminum exposure remains controversial [7]. In our pig model, quantitative histology showed a decrease in the number of osteoblasts [22]. Animal [8] and human studies [18] have shown that another adverse effect of aluminum on bone cells is primary failure of matrix synthesis during aluminum loading.

Besides the diminished rate of bone formation, aluminum has been shown to induce defective mineralization of osteoid. Aluminum may directly inhibit the calcification of osteoid, as suggested by the fact that aluminum localizes predominantly within the mineralization front $[5,6]$ and reduces the uptake of tetracycline into bone. Another mechanism by which aluminum can interfere with the proper mineralization of osteoid is by acting as a physical-chemical inhibitor of mineralization. In vitro, aluminum diminishes the formation and growth of hydroxyapatite crystals in a concentration-dependent manner in a cell-free system [3, 23].

In summary, aluminum is deposited in bone and induces osteomalacia in the absence of renal failure. Radiographs show areas of sclerosis in the metaphysis and at the periphery of the epiphysis and separation of the anterior tibial tubercle (avulsion fracture). The growth plate did not widen in the treated group in our study.

\section{References}

1. Andreoli SP, Bergstein JM, Sherrard DI (1984) Aluminum intoxication from aluminum-containing phosphate binders in children with azotemia not undergoing dialysis. $N$ Engl J Med 310:1079

2. Andreoli SP, Smith JA, Bergstein JM (1985) Aluminum bone disease in children: Radiographic features from diagnosis to resolution. Radiology 156:663

3. Blumenthal NC, Posner AS (1984) In vitro model of aluminum induced osteomalacia: Inhibition of hydroxyapatite formation and growth. Calcif Tissue Int $36: 439$

4. Botella J, Gallego JL, Fernandez-Fernandez J, Sanz-Guajardi D, de Miguel A, Ramos J, Franco P, Enriques R, Sanz-Moreno C (1984) The bone scan in patients with aluminum-associated bone disease. Proc EDTA-ERA $21: 403$

5. Cournot-Witmer G, Zingraff J, Bourdon R, Druecke T, Balsam S (1979) Aluminium and dialysis bone disease. Lancet 2:795

6. Denton J, Freemont AJ, Ball J (1984) Detection and distribution of aluminum in bone. J Clin Pathol 3-7:136

7. Goodman WG (1985) Bone disease and aluminum: Pathogenic considerations. Am J Kidney Dis 6:330

8. Goodman WG, Giligan J, Horst R (1984) Short-term aluminum administration in the rat: Effects on bone formation and relationship to renal osteomalacia. J Clin Invest 73:171

9. Gorsky JE, Dietz AA, Spencer H, Osis D (1979) Metabolic balance of aluminum studied in six men. Clin Chem 25:1739

10. Ihle B, Becker $G$ (1985) Gastrointestinal absorption of aluminum. Am J Kidney Dis 6:302

11. Ihle B, Buchanan M, Stevens B, Marshal A, Plomley R, d'Apice A, Kincaid-Smith P (1982) Aluminum associated bone disease: Clinico-pathologic correlation. Am J Kidney Dis 2:255

12. Klein GL, Targoff CM, Ament ME, Sherrard DJ, Bluestone R, Young JH, Norman AW, Coburn JW (1980) Bone disease associated with total parenteral nutrition. Lancet 2:1041

13. Klein GL, Alfrey AC, Miller NL, Sherrard DJ, Hazlet TK, Ament ME, Coburn JW (1982) Aluminum loading during total parenteral nutrition. Am J Clin Nutr 34:1425

14. Ott SM (1985) Aluminum accumulation in individuals with normal tenal function. Am J Kidney Dis 6:297

15. Ott SM, Maloney NA, Coburn JW, Alfrey AC, Sherrard DJ (1982) The prevalence of bone aluminum deposition in renal osteodystrophy and its relation to the response to calcitriol therapy. N Engl J Med 307:709

16. Ott SM, Maloney NA, Klein GL, Alfrey AC, Ament ME, Coburn JW, Sherrard DJ (1983) Aluminum is associated with low bone formation in patients receiving chronic parenteral nutrition. Ann Intern Med 98:910

17. Recker RR, Blotcky AJ, Leffler JA, Rack EP (1977) Evidence for aluminium absorption from the gastrointestinal tract and bone deposition by aluminium carbonate ingestion with normal renal function. J Lab Clin Med 90:810

18. Ricanati ES, Ott SM, Klein KL, Alfrey AC, Sherrard DJ, Coburn JW (1982) Evaluation of bone in dialysis patient exposed to aluminum in dialysate. Kidney Int $21: 176$

19. Sebes JI, Pinstein ML, Massie JD, Scott RL, Palmieri GM, Williams JW, Acchiardo SR (1984) Radiographic manifestations of aluminum-induced bone disease. AJR 142:424

20. Sedman AB, Miller NL, Warady BA, Lum GM, Alfrey AC (1984) Aluminum loading in children with chronic renal failure. Kidney 26:201

21. Sedman AB, Klein GL, Merritt RJ, Miller NL, Weber KO, Gill WL, Anand H, Alfrey AC (1985) Evidence of aluminum loading in infants receiving intravenous therapy. $\mathrm{N}$ Eng1 J Med 312:1377

22. Sedman AB, Alfrey AC, Miller NL, Goodman WG (1987) The tissue and cellular basis for impaired bone formation in aluminum-related osteomalacia. J Clin Invest 79:86

23. Siegel N (1985) Aluminum interaction with biomolecules: The molecular basis for aluminum toxicity. Am J Kidney Dis $6: 353$ 